\title{
Tailoring cross-sectional energy-efficiency measures to target groups in industry
}

\author{
Katharina Wohlfarth $(\mathbb{D}$ - Wolfgang Eichhammer • \\ Barbara Schlomann • Ernst Worrell
}

Received: 25 April 2017 / Accepted: 17 January 2018 /Published online: 6 March 2018

(C) The Author(s) 2018. This article is an open access publication

\begin{abstract}
The improvement of energy efficiency in industrial companies plays a crucial role for the energy transition. Although significant economic potentials have been identified, the concerned actors are still struggling to realize them fully. To support the implementation of energy efficiency measures by passing policies, a deeper understanding of the barriers affecting different kinds of companies is necessary to better match the options to their needs and requirements. This paper considers companies' characteristics and barriers to draw conclusions on energy efficiency policies and specific recommendations on energy efficiency measures. It recommends compromises for policies between high administrative efforts to design individual solutions for companies and too generic approaches, which are not tackling the specific barriers and companies' characteristics. Our analysis assesses monitoring data of 263 enterprises of the Learning Energy Efficiency Networks LEEN in Germany. The LEEN support energy audits, company networking and assesses implemented energy efficiency measures. Lack of information combined with
\end{abstract}

Electronic supplementary material The online version of this article (https://doi.org/10.1007/s12053-018-9619-7) contains supplementary material, which is available to authorized users.

K. Wohlfarth $(\bowtie) \cdot$ W. Eichhammer $\cdot$ B. Schlomann Fraunhofer Institute for Systems and Innovation Research ISI, Breslauer Straße 48, 76139 Karlsruhe, DE, Germany e-mail: Katharina.Wohlfarth@isi.fraunhofer.de

W. Eichhammer · E. Worrell

Copernicus Institute of Sustainable Development, Utrecht

University, Heidelberglaan 2, 3584 CSUtrecht, The Netherlands unfavourable reasoning in decision-making impedes the adoption of profitable measures. Thus, financial policy instruments should aim at promoting long-term decisionmaking. Audits turned out to be an effective information tool and are more common in LEs than in SMEs. Accordingly, the number of implemented measures and the choice of specific measures relate to company size. Regarding barriers to energy efficiency measures, we found financial barriers most prevalent, but there was no general correlation with company size. Moreover, financial restrictions are not necessarily caused by a lack of money, but also by risk aversion or unlikely payback periods. LEs are stronger affected by motivational barriers, especially if the expected organizational effort is high. Reducing transaction costs can increase the willingness to invest greater efforts in energy efficiency measures.

Keywords Energy-efficiency measures · Barriers · Cross-sectional technologies - Manufacturing sector . Energy-efficiency policies

\section{Introduction}

Studies on energy efficiency and improving energy performance typically encounter the so-called "energy efficiency gap" (Jaffe and Stavins 1994; Stern 1992), which is often referred to as the difference between the status quo and economically attractive energy-efficiency improvements. Barriers impeding improvements in energy efficiency issues need to be lowered to bridge this 
gap. A number of studies have already revealed the considerable potentials of energy-efficiency measures (Blok 2004; Grenade et al. 2009; Worrell et al. 2009; Fraunhofer ISI et al. 2014; Ecofys and Fraunhofer ISI 2010; Eichhammer 2013). Accordingly, improving energy efficiency has received increasing attention in energy policy in many countries (IEA 2012).

The technical potential of EEMs (energy efficiency measures) in companies is limited by the available processes or technologies where measures can be applied. However, previous studies have already shown that nontechnical barriers tend to be the main obstacle to implementing EEMs (IEA 2012). The energy efficiency gap must be ascribed to barriers that are associated with internal routines, procedures or decision-making, ways of reasoning, organizational or financial possibilities, and external restrictions (cp. Sorrell et al. 2011). Recent research differentiates between economic, informationrelated, organizational, behavioural, competence-related, technology-related, and awareness barriers (Cagno et al. 2013). Previous work has shown that companies often have misconceptions about the profitability of energy efficiency measures - taking risk indicators such as the payback period as a profitability indicator (Schöter et al. 2009). Especially if energy intensity is low, improvements in energy efficiency might be underrated (Harris et al. 2000; Cooremans 2013), possibly due to a lack of information to fully assess its value. Especially SMEs might not be able to reduce their uncertainties because of lack of time and money to afford these transaction costs (Stern and Aronson 1984). Providing information first and then accompanying the steps of the implementation process of measures can lead to significant improvements in energy efficiency despite the existence of other, not only informational barriers (cp. Wohlfarth et al. 2016). Trianni et al. (2016) provide an overview of empirical studies on barriers to industrial energy efficiency, highlighting the influence of different barriers in the decision making process. These aspects should also be taken into account when EEMs are suggested.

The persistence of these barriers is one important justification for the introduction of policy instruments ${ }^{1}$ in the field of energy efficiency aiming at overcoming

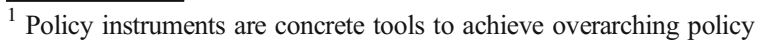
objectives such as the removal of barriers. The term 'instrument', can also be described in studies as 'implementing measures', 'programs', 'policies', or 'policies and measures' (for a comprehensive overview see Rogge and Reichardt, 2013).
}

the barriers and thus fully exploiting the cost-effective potential. Typically, regulative, informative, and economic policy instruments can be distinguished (Rogge and Reichardt, 2013). Policy measures can predominantly be classified as financial or informational/ educational measures, while the majority of the existing measures fall under the category of financial measures (funds, loans, subsidies, financial support schemes, subsidised consultations, financial incentives and aids). Informational/educational measures include resource planning and management and the behavioural training of employees towards more responsible energy-related practices (Lapillonne et al. 2015). An overview of typical barriers and remedial policy tools give IEA (2012) and EEFIG (2015). Cagno et al. (2015) show exemplary energy efficiency policies and the affected drivers. They also point out the importance of a common understanding of drivers and barriers between enterprises, government, and other external organisations to develop mechanisms and policies successfully. Ringel et al. (2016) and Fleiter (2013) give indications of the saving potential, which can be exploited by the respective policies.

However, each of these instruments usually only addresses some of the barriers. Therefore, several policy studies in the field of environmental research have argued for the need to combine different policy instruments in so-called policy mixes (see Rogge and Reichardt, 2013, for an overview). Concepts like the German National Plan for Energy Efficiency (NAPE) combine instruments for information and market transparency, financial incentives, and regulations in a broad policy mix to address different barriers and enhance the implementation of EEMs. A suitable policy mix to support the implementation of energy-saving measures in companies might also make use of rarely addressed driving forces like social and psychological factors (e.g., improved motivation of energy managers, environmental awareness or a better public image, $\mathrm{cp}$. Lapillonne et al. 2015).

It is already known that companies' characteristics influence implementing EEMs, e.g., manufacturing companies are more active than those from the tertiary sector (DeCanio and Watkins 1998) and larger companies are usually more likely to invest in energy-efficiency technologies (ib., Florax et al. 2011; Trianni and Cagno 2012; Arens and Worrell 2014). A policy instrument differentiating between companies' characteristics (in this case companies' size) by addressing informational deficits, is 
Article 8 of the Energy Efficiency Directive EED (EC 2012). Since 2015 it has required Member States to implement a four-yearly energy audit obligation for LEs and to develop programmes to encourage small or SMEs ${ }^{2}$ to voluntarily undergo energy audits and to implement audit recommendations. Although audits for SMEs are not mandatory, they seem especially important as SMEs are usually less aware of EEM options (cp. Table 2) and therefore tend to underestimate their potential (Gruber and Brandt 1991; Frahm et al. 2010). It should be noted that the majority of companies in Germany belong to the category of SMEs (Statistisches Bundesamt 2013), as in most countries. The energy consumption of an SME is indeed lower than that for LEs in the same sector, but in sum, they remain important energy consumers. Their potential for energy efficiency improvements is typically more cost-effective, as it is largely untapped and improvements can be made with lesser effort (IEA 2015; Thollander et al. 2014). While several EEMs are already in place in a variety of countries for SMEs (cp. Price and Lu 2011; Fleiter et al. 2012; IEA 2015), more tailored programmes are needed to deal with their special needs (Trianni and Cagno 2012; Trianni et al. 2016).

In order to give recommendations for policies, a connection between types of companies and barriers should be drawn to identify specific target groups for specific policy measures. According to Stern and Aronson (1984), effective information is specific and personal, so the aim is to personalize and specify EEMs to target groups. The idea is to differentiate policies and EEMs more adequately without the need of an individual audit for every single company. This more general approach could be a marketing strategy that reduces the effort needed for searching and information processes and could also serve as the basis for recommendations addressing company-types on a larger scale. On the other hand, knowing about the differences between target groups allows the promotion of energy efficiency policies to be tailored to their needs.

Hence, taking SMEs into the focus, the research questions of this paper are:

- Which kind of barriers hindering the implementation of EEMs are the most prevalent and are they related to specific types of companies?

\footnotetext{
${ }^{2}$ The definition criteria for SMEs are in this case: number of employees, turnover and balance sheet total (EC 2003).
}

- On which general company characteristics (like size, energy costs, or autonomy in decision making) does the potential to implement measures depend?

- Are specific measures a better fit for specific kinds of companies?

- How can the present policy mix addressing companies be improved based on the results of our analysis?

\section{Methods and database}

Methods

For our analyses, we use evaluation data from a project that aimed to identify and implement EEMs in companies-namely from LEEN "Learning Energy Efficiency Networks" (Jochem and Gruber 2007; Rohde et al. 2015)_focusing on companies from the manufacturing sector. The LEEN addressed small and medium-sized enterprises (SME) and large enterprises (LE).

We analyse the relations between companies' characteristics and barriers respectively implemented measures to find categories of target groups and suitable support measures. We compare SMEs with LEs in a more detailed analysis and try to derive policy implications from our results. Rating scales for barriers during the implementation process of EEMs as well as the number of implemented measures and a broad collection of company characteristics for SMEs and LEs were taken from the LEEN data. The items for barriers were worked out by the project team based on long-time experience with comparable projects (Jochem et al. 2006; Jochem and Gruber 2007; cp. DiNucci 2012). The categorization of measures (cp. Table 7) was developed within a bachelor thesis (Leinweber 2014) by clustering those measures that were recorded during the monitoring of the project by the criteria 'kind of measure' and 'location of implementation'. The technologies the categorized measures refer to are thereby treated as an entity, i.e. measures are not counted twice (e.g., measures on pumps are not included in measures on refrigeration although the refrigeration system may contain pumps).

Besides descriptive statistics, we used factor analysis to describe the relevant dimensions of barriers to the implementation of measures. Factor analysis is a method to reduce complexity in data by combining similar variables to factors which describe different underlying 
Table 1 Available data from LEEN used for the analyses
Total available data for Data available from Data available on companies from the evaluating survey implemented measures manufacturing sector
Number of participants 263
160

137 concepts. Above all, we tried to draw connections between companies' characteristics and variables of interest (like barriers or the number of implemented measures) using regression analyses. A regression analysis estimates the relationship between variables - a dependent variable and different independent variables (here companies' characteristics). The aim is to understand how the dependent variable changes when the independent variables vary (see Howell 2012).

The formula for a regression analysis can be expressed as:

$$
\begin{aligned}
\hat{y}_{i}=a & +\sum_{j} \beta_{j} \cdot x_{i, j}(\text { for } \mathrm{i}=1, \ldots, \mathrm{N} \text { and } \mathrm{j} \\
& =\text { number of independent variables })
\end{aligned}
$$

Where $\hat{y}_{i}$ represents the estimated value of the dependent variable, $x_{i, j}$ the independent variables, $\beta_{j}$ are the weighted factors belonging to the independent variables and $a$ represents a constant.

To analyse differences between subgroups, we used $t$ tests - a method that analyses differences of means for significance.

\section{Database}

Our analysis is based on detailed monitoring data from the scientific evaluation of the Learning Energy Efficiency Network process in Germany between 2009 and 2014. Participants in such a network are committed to regularly exchange experiences in regional groups of 10-15 companies and to set themselves a voluntary energy saving target for the next 3-4 years. The networks are assembled not to include companies within market competition; that is also why, especially, crosssectional EEMs are in the focus of our research. The participating companies pay a fee to finance the energy audit, network meetings and monitoring. For our analysis, we especially drew on the evaluating survey data collected towards the end of the networking process (second half of 2013) and monitoring data on the implemented measures in each company. We merged these data for our purpose, but due to the different sources, available data may differ for the individual companies (Table 1).

Those companies can be assigned to the manufacturing sector (NACE classification sector $\mathrm{C}^{3}$ ), especially the subsectors manufacture of food products (NACE 10 ), chemicals and chemical products (NACE 20), rubber products (NACE 22), basic metals (NACE 25) and machinery and equipment n.e.c (NACE 28) (each between 7.6 and $13.3 \%$, remaining subsectors with smaller shares). These rather small groups of subsectors impeded analyses based on subgroups within the manufacturing sector. Therefore, conclusions on the influence of core businesses and underlying production processes are hardly possible for our dataset. We tried to consider structural effects anyway by grouping subsectors by energy intensity of their processes (Table 9 in the attachments). The categorization resulted in 19\% companies with low energy-intensive processes, $44 \%$ with medium energy-intensive processes and $37 \%$ with high energy-intensive processes. We use category 2 as the reference category for our regression analyses.

The set of companies is not representative regarding the shares of company size (cp. Table 2). This is because participation in the LEEN was recommended especially to medium-sized and large companies with annual energy costs between $€ 0.5$ and 50 million because otherwise participation in the networks would have been too costly for companies in comparison to expected savings.

\section{Results}

The influence of barriers

We first evaluated LEEN participants' ratings of the barriers at the end of the networking process, asking which ones were observed during the network phase. Therefore, those barriers refer to the perspective of the companies as energy consumers (not to manufacturers

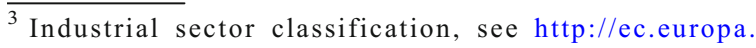
$\mathrm{eu} /$ competition/mergers/cases/index/nace_all.html
} 
Table 2 Overview of analysed datasets

\begin{tabular}{llll}
\hline & \multicolumn{2}{l}{ Learning Energy Efficiency Networks LEEN } & \\
\cline { 2 - 4 } $\begin{array}{l}\text { Data described as mean (Median Md; } \\
\text { Standard Deviation SD) }\end{array}$ & $\begin{array}{l}\text { Total number of manufacturing } \\
\text { companies (Md; SD) }\end{array}$ & SME (Md; SD) & LE (Md; SD) \\
\hline Number of companies (N) & $263^{\mathrm{a}}$ & 95 & 150 \\
Number of employees per company & $635(331 ; 957)^{\mathrm{b}}$ & $122(119 ; 65)$ & $961(565 ; 1108)$ \\
Energy costs m $€$ & $2.95(1.54 ; 4.44)$ & $1.34(0.68 ; 2.01)$ & $4.07(2.38 ; 5.35)$ \\
Energy intensity (MWh/ employee) & $183.97(49.01 ; 463.71)$ & $259.24(75.13 ; 583.47)$ & $135.98(43.01 ; 361.77)$ \\
Implemented measures per company & $12(8 ; 10.7)$ & $8.48(6 ; 7.7)$ & $13.87(11 ; 11.8)$ \\
Audit already conducted $(\%)$ & 48.4 & 37.2 & 56.9 \\
Share of cluster $1 ; 2 ; 3(\%)$ & $19 ; 44 ; 38$ & $12 ; 37 ; 52$ & $23 ; 48 ; 29$ \\
\hline
\end{tabular}

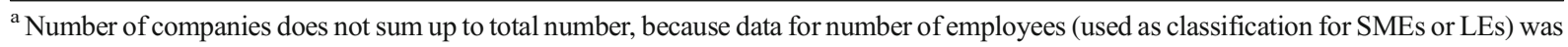
not given for all companies.

${ }^{\mathrm{b}}$ due to the large spread we assume that some indicated employees for the whole corporation

Definitions of companies' sizes: SME ( $<250$ employees); LE ( $\geq 250$ employees).

of energy efficiency technologies, consultants, or banks). This especially concerns the barrier measures not profitable, because the energy consultants expect the suggested measures to be profitable. The rating given for this category reflects the perception of the person in charge within the company, which might be different to the one of the consultant (e.g., due to internal rates of return). Figure 1 shows the mean ratings as well as the overall ranking of barriers. Technology supplier cannot deliver, ${ }^{4}$ missing information or market overview and management hard to convince are ranked the lowest, which is comprehensible because technologies for suggested measures were available and one main issue within the network process was delivering information. Concerning management approval, one can assume that management was already generally convinced of the idea of implementing efficiency measures, because this was the purpose of the project they chose to participate in.

The barriers ranked the highest mostly concern issues of time and money with a clear emphasis on financial restrictions: Measures not profitable, limited financial possibilities, concerned parties lack time and priorities on other investments. The difference between difficulties in implementation and the higher ranked barriers with values greater than 3 turned out to be significant $\left(\mathrm{T}(157)=2.653^{* *}\right) .^{5}$

\footnotetext{
${ }^{4}$ This refers to material and technology needed to implement the energy efficiency measure of interest.

${ }^{5}$ level of significance: $*=p \leq .05, * *=p \leq .01 ; * * *=p \leq .001$
}

Overall, the ratings are quite moderate with a mean of 2.7 on a scale from 1 to 5 (1: a low rating of the barrier; 5: a high rating). One should note that, at the end of the project, over $96 \%(N=153)$ of the participants that completed the last survey reported that they implemented at least some of the suggestions resulting from the network process. This supports the assumption that the networks did well in addressing possible barriers. This also means that the barriers stated here did not prevent measures in general, but did at least hinder the process or impede the implementation of additional suggested measures beyond those that have been implemented.

We assume that usually more than one barrier affects companies when they are struggling to implement measures, and that some barriers are more likely to co-occur. The simple ranking of barriers does not indicate which aspects interact or are interrelated from the participants' perspective. Therefore, we conducted a factor analysis with the aim to find underlying structures and contentrelated categories in the ratings of barriers mentioned by the participants. Table 3 shows the resulting four factors which consist of co-occurring barriers.

The identified factors are in line with taxonomies of barriers in other studies. Compared to one of the later taxonomies introduced by Cagno et al. (2013), which distinguishes economic, information-related, organizational, behavioural, competence-related, technology-related, and awareness barriers, we found some of these categories concurred in our case. We therefore used a smaller set of items on which to base our categories. We assigned economic barriers to "financial/ economic 


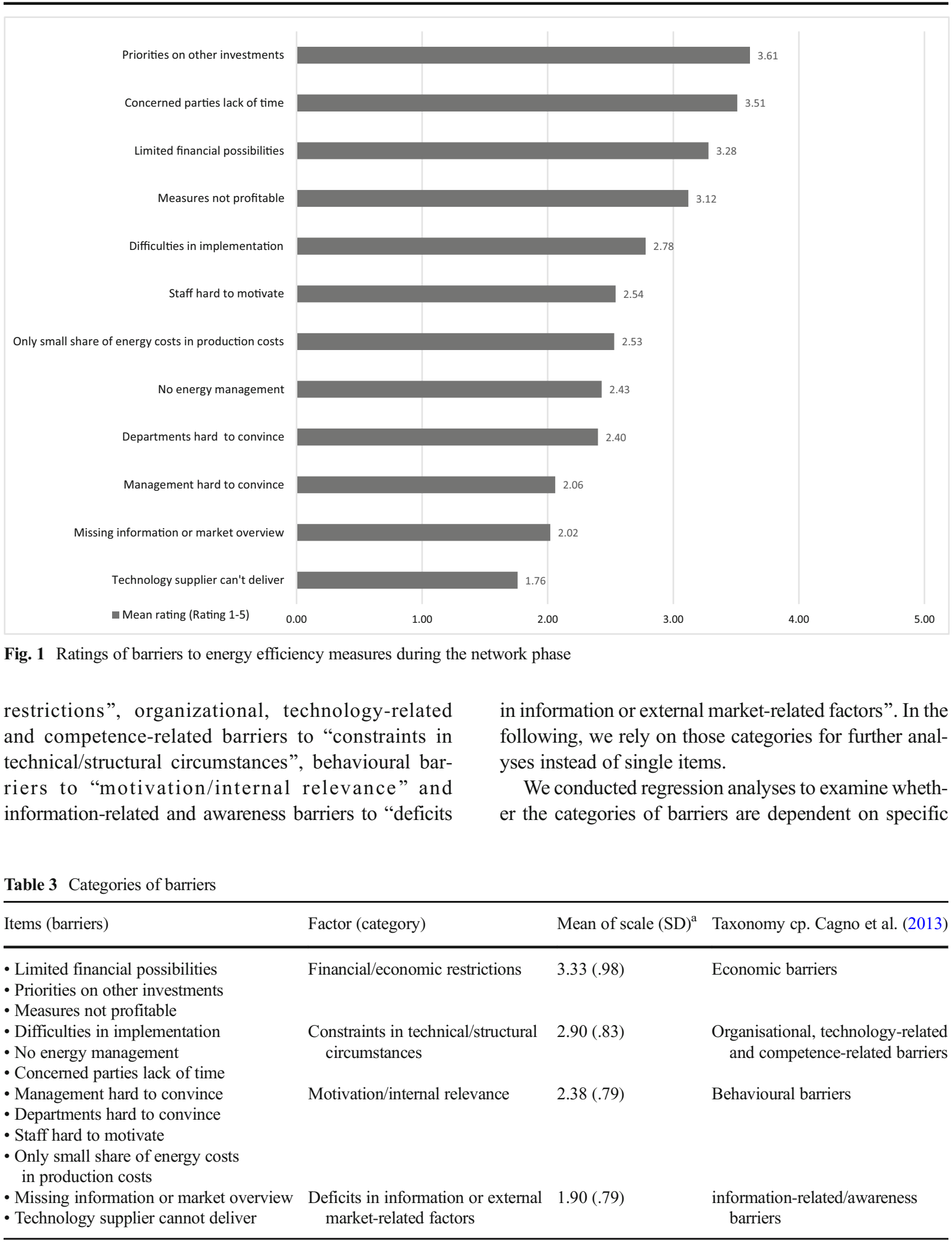

${ }^{a}$ The means of scales do not differ in their ranking order comparing SME and LE

Bartlett's sphericity test chi $^{2}(66)=343.0 ; p<.001$; Kaiser-Meyer-Olkin measure $=.612$ (moderate, Kaiser and Rice 1974). 
characteristics of the participating companies, using barriers as the dependent variable. The following company characteristics were treated as independent variables: number of employees, energy intensity (annual MWh per employee), energy costs, autonomy of enterprise, relatedness to customer, and how EEM decisions are made (stating that the decision is influenced by organizational effort, profitability calculation, amount of expenses or else) (Table 4).

The analysis showed that especially motivational and financial barriers are more prevalent in specific kinds of companies (Table 4): Larger companies, companies with lower energy costs and companies that do not belong to those with energy-intensive processes (cluster 3 ) tend to face motivational barriers to a higher degree. We assume that more effort is required to motivate a larger number of employees resp. the management of LEs and that lower energy costs act as a demotivating force as well as missing energy-intensive processes where saving potential could be found. Autonomous companies (which might be able to make decisions concerning expenses on their own) face financial barriers to a lesser extent as well as companies that do not base their EEM decisions on expenses only. This suggests that the way of decision-making affects the barriers to EEMs.

Regulations, directives, and entitlements sometimes distinguish between company types mainly based on company size. Our analysis showed that company size has a highly significant influence on at least one of the barrier factors. We assume that the influencing variables differ within different kinds of companies, so in order to reveal other factors, which might be overlooked under the influence of the number of employees, we decided to conduct the same regression analyses within the two subgroups of SMEs and LEs (cp. Table 2 for group sizes and information on their characteristics). Table 5 shows the results.

This more detailed analysis reveals differences between SMEs and LEs concerning characteristics that influence barriers. Comparing the results for SMEs and LEs, the effects of characteristics are more strongly and more frequent for SMEs, indicating a larger heterogeneity within that category. Energy intensity, the number of employees and small energy costs indicate greater motivational barriers for SMEs. The analysis shows that energy intensity and energy costs are perceived differently. While high-energy costs serve as a motivating factor, high energy intensity in SMEs can have the opposite effect. High energy intensity means high consumption for few employees - indicating energy consumption being a (mostly) inevitable part of the core business and/or possibly no persons for energy management in charge. In particular, small enterprises are more likely not to have a person responsible for energy issues, which might also explain motivational barriers. Compared to high energy costs, high energy intensity alone may therefore not be sufficient to motivate companies to introduce changes. As for this subgroup of SMEs as for the complete sample, a larger number of employees seems harder to be motivated while higher energy costs can serve as a motivating factor. For LEs, motivational barriers occur when a great organizational effort is expected, e.g., the activity of responsible or affected employees. For LEs, too, a larger number of employees is harder to motivate, perhaps due to associated more complex decision chains and involved parties. In SMEs, financial barriers are perceived to be higher if EEM decisions are based only on the amount of expenses rather than other reasons. Having the mere

Table 4 Factors influencing barriers

\begin{tabular}{lll}
\hline Factor & Variables of significant influence $(\beta)$ & Model quality \\
\hline Financial/economical restrictions & $\begin{array}{l}\text { Decision based on amount of expenses** }(0.18) \\
\text { Autonomy of enterprise*1 }(0.13)\end{array}$ & $\mathrm{F}(10)=2.513^{* *}, R^{2}=.091(.055)$ \\
Constraints in technical/structural circumstances & n.s. \\
Motivation/internal relevance & $\begin{array}{l}\text { Number of employees*** }(0.26) \\
\text { Energy costs* }(-0.18)\end{array}$ & $\mathrm{F}(10)=2.330^{* *}, R^{2}=.084(.048)$ \\
$\begin{array}{l}\text { Cluster subsector 3 }(-0.15) \\
\quad \text { related factors }\end{array}$ & & n.s. \\
\hline
\end{tabular}

$R^{2}$ : explained variance; $F$ : test value for significance; level of significance: $*=p \leq .05, * *=p \leq .01 ; * * *=p \leq .001$

${ }^{1} 0$ : autonomous, 1 : part of another corporation. Relatedness to customer means that products are directly supplied to end customers. 
Table 5 Factors influencing barriers in SME and LE based on LEEN

\begin{tabular}{|c|c|c|c|c|}
\hline \multirow[t]{2}{*}{ Factor } & \multicolumn{2}{|l|}{ SME } & \multicolumn{2}{|l|}{ LE } \\
\hline & $\begin{array}{l}\text { Variables of significant } \\
\text { influence }(ß)\end{array}$ & Model quality & $\begin{array}{l}\text { Variables of significant } \\
\text { influence }(B)\end{array}$ & Model quality \\
\hline Financial /economic restrictions & $\begin{array}{l}\text { Decision based on amount } \\
\text { of expenses*** }(0.46)\end{array}$ & $\begin{aligned} \mathrm{F}(10) & =3.671 * * * \\
R^{2} & =.304(.221)\end{aligned}$ & & n.s. \\
\hline $\begin{array}{l}\text { Constraints in technical } \\
\text { /structural circumstances }\end{array}$ & $\begin{array}{l}\text { Number of employees** }(0.36) \\
\text { Energy costs* }(-0.35) \\
\text { Decision based on amount } \\
\text { of expenses* }(0.27) \\
\text { Decision based on } \\
\text { organizational effort** } \\
(0.30)\end{array}$ & $\begin{aligned} \mathrm{F}(10) & =2.335^{*} \\
R^{2} & =.217(.124)\end{aligned}$ & & n.s. \\
\hline Motivation/internal relevance & $\begin{array}{l}\text { Energy intensity** }(0.46) \\
\text { Number of employees* }(0.26) \\
\text { Energy costs* }(-0.40)\end{array}$ & $\begin{aligned} \mathrm{F}(10) & =2.607 * * \\
R^{2} & =.237(.146)\end{aligned}$ & $\begin{array}{l}\text { Number of employees* } \\
(0.21) \\
\text { Decision based on } \\
\text { organizational effort** } \\
(0.25)\end{array}$ & $\begin{aligned} \mathrm{F}(10) & =2.505 * * \\
R^{2} & =.153(.092)\end{aligned}$ \\
\hline $\begin{array}{l}\text { Deficits in information or } \\
\text { external market-related factors }\end{array}$ & & n.s. & $\begin{array}{l}\text { Decision based on amount } \\
\text { of expenses** }(-0.27)\end{array}$ & $\begin{aligned} \mathrm{F}(10) & =2.388^{*} \\
R^{2} & =.147(.085)\end{aligned}$ \\
\hline
\end{tabular}

$R^{2}$ : explained variance; $\mathrm{F}(\mathrm{df})$ : test value for significance.

Level of significance: $*=p \leq .05 ; * *=p \leq .01 ; * * *=p \leq .001$.

sum of money in mind, expensive measures which are profitable in the long rum might be impeded. Informational or market-related factors of EEMs in LEs seem to fade into the background if decisions are based on the amount of expenses. We assume that affordability and profitability resp. payback periods play a stronger role for decision-making than more external factors. For SMEs, constraints in circumstances like difficulties in implementation or lack of time are associated with a larger number of employees, low energy costs (that might not justify the effort), and if decisions are based on the amount of expenses or (quite reasonably) on organisational effort.

Factors influencing the implementation of measures

Complementary to the analysis of companies' characteristics concerning barriers, we also conducted a comparable regression analysis for the absolute number of measures the companies implemented (dependent variable) to find out whether becoming more energy efficient is easier for certain kinds of companies than for others.

Our result shows that the number of implemented measures usually increases with the number of employees (Table 6), most likely due to a concomitant larger production site, i.e., more facilities and technologies available for EEMs. The effect has a low level of explained variance resp. is only relevant for large differences in the number of employees. This prompts why no such effect was found within the subgroups of SMEs and LEs. In contrast to companies' characteristics, a similar regression analysis examining the influence of stated barriers on the number of conducted measures revealed no significant results. We do not imply that perceived barriers had no influence on the process of implementing efficiency measures, but with this result in mind, we did hypothesize that companies facing specific barriers tend to implement different measures than companies facing other barriers. If barriers vary between EEMs, this information can be useful when suggesting EEMs to companies facing specific barriers (cp. Sorrell et al. 2011; Cagno and Trianni 2014). We used $t$ tests to see whether the values of stated barrier dimensions and other characteristics varied between those companies that conducted specific types of measures and those that did not (Table 7).

VAC (ventilation and air-conditioning) measures are more often implemented by larger companies with lower energy intensity which can be expected, as these characteristics prompt a higher importance of energy consumption due to building issues than for processes. The dimensions of VAC are probably correlated with the number of employees and therefore makes such measures more 
Table 6 Regression on number of implemented measures

\begin{tabular}{lll}
\hline Factor & Variables of significant influence $(ß)$ & Model \\
\hline Number of implemented measures & Number of employees** $(0.22)$ & $\mathrm{F}(10)=2.466^{* *}, R^{2}=.089(.053)$ \\
\hline
\end{tabular}

$R^{2}$ : explained variance; $\mathrm{F}(\mathrm{df})$ : test value for significance.

Level of significance: $*=p \leq .05$, ** $=p \leq .01 ; * * *=p \leq .001$.

profitable in larger companies. Organisational measures (such as staff motivation) also seem more sensible and maybe more necessary given a larger number of employees. Lighting or compressed air measures seem to be feasible with lesser effort resp. Support of the staff as they are especially implemented in companies with high motivational barriers. Measures concerning the building envelope can also be suitable for companies that lack technologies with energy efficiency potential or if they have low energy intensity. The latter might apply as well to the use of waste heat. Change or control of motors and pumps seem to be measures which can be implemented with comparatively low organisational effort.

Measures dealing with process heat or an energy carrier change usually deliver the highest absolute savings. On the other hand, these measures also require high investments (Rohde et al. 2015). Cost-effective saving potentials in industry can be found especially in the field of cross-cutting technologies such as motors (fans, pump systems, cooling devices, compressed air systems) and electricity-driven system optimisation or CHP (Lapillonne et al. 2015).

Figure 2 compares the share of implemented measures in SMEs and LEs. Differences in specific measures occur, e.g., for the production of heat, VAC and distribution of heat, cooling and compressed air, which are all conducted more by LEs than SMEs. In general, lighting, distribution of heat, cooling and compressed air and motors and pumps are among the most implemented EEMs in SMEs. The figure shows, that some measures are more common than others although the concerned technologies are available to all companies (e.g. efficiency measures concerning lighting compared to measures concerning the building envelopeindicating that lighting measures can be conducted with

Table 7 Energy efficiency measures and company characteristics influencing implementation

\begin{tabular}{|c|c|c|c|}
\hline Energy efficiency measure & $\begin{array}{l}\text { Company characteristics influencing } \\
\text { measure implementation }\end{array}$ & $\begin{array}{l}\text { Average difference in company } \\
\text { characteristics }\end{array}$ & $\begin{array}{l}\text { Test value for } \\
\text { significance }\end{array}$ \\
\hline Production of heat & - & & \\
\hline refrigeration & - & & \\
\hline $\begin{array}{l}\text { Ventilation and air-conditioning } \\
\text { technology (VAC) }\end{array}$ & $\begin{array}{l}\text { Larger number of employees } \\
\text { Lower energy intensity } \\
\text { Less often cluster } 3\end{array}$ & $\begin{array}{l}488 \text { vs. } 1122 \\
283.48 \text { vs. } 102.47 \mathrm{MWh} / \mathrm{empl} \text {. } \\
41 \% \text { vs. } 30 \%\end{array}$ & $\begin{array}{l}\mathrm{T}(44.0)=-2.449 * \\
\mathrm{~T}(108.2)=2.390 * \\
X^{2}(1 ; 137)=6.58^{*}\end{array}$ \\
\hline Lighting & Higher motivational barriers & 2.22 vs. 2.66 & $\mathrm{~T}(83)=-2.654 * *$ \\
\hline Compressed air & Higher motivational barriers & 2.31 vs. 2.69 & $\mathrm{~T}(83)=-2.312 *$ \\
\hline Building envelope & $\begin{array}{l}\text { Lower energy intensity } \\
\text { More often in cluster } 2\end{array}$ & $\begin{array}{l}267.62 \text { vs. } 80.98 \mathrm{MWh} / \mathrm{empl} \text {. } \\
41 \text { vs. } 58 \%\end{array}$ & $\begin{array}{l}\mathrm{T}(115.2)=2.822 * * \\
X^{2}(1 ; 137)=4.90 *\end{array}$ \\
\hline Utilisation of waste heat & Lower energy intensity & 291.89 vs. $118.81 \mathrm{MWh} / \mathrm{empl}$ & $\mathrm{T}(89.5)=2.139 *$ \\
\hline Motors and pumps & Higher organisational barriers & 2.88 vs. 3.23 & $\mathrm{~T}(83)=-2.082 *$ \\
\hline $\begin{array}{l}\text { Distribution of heat, cooling } \\
\text { and compressed air }\end{array}$ & - & & \\
\hline Organisational measures & Larger number of employees & 449 vs. 908 & $\mathrm{~T}(84.3)=-2.582 *$ \\
\hline Other measures & Higher energy intensity & 119.24 vs. $296.10 \mathrm{MWh} / \mathrm{empl}$ & $\mathrm{T}(111.5)=-2.035^{*}$ \\
\hline
\end{tabular}

Level of significance: $*=p \leq .05, * *=p \leq .01 ; * * *=p \leq .001$.

Independent variables: Barriers, number of employees, energy intensity.

Barriers measured on a scale of 1 to 5, energy intensity: MWh/employee, cluster: share within cluster that implemented concerning EEM compared to share in other cluster. 


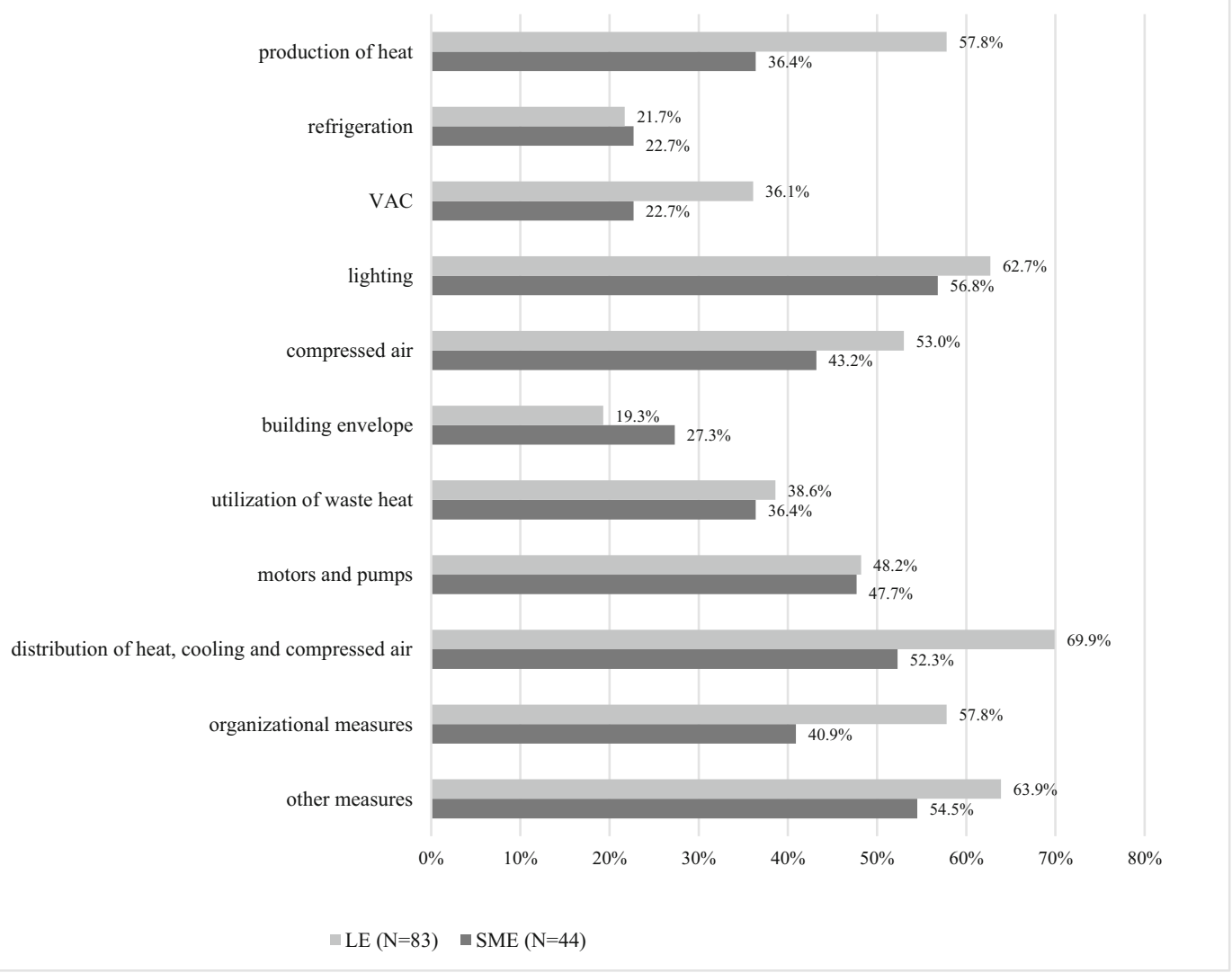

Fig. 2 Comparison of implementation rate of measures for SMEs and LEs within LEEN

much lesser effort). As stated above, LEs usualy conduct more measures, but the rates of implementation are not always in relation (comparing measures on motors and pumps with production of heat). In few cases, measures are more common for SMEs (esp. measures for the building enveope).

When interpreting these results, one should bear in mind that there might be structural differences between the subgroups of SMEs and LEs, e.g., there is a larger share of companies with energy-intensive processes (cluster 3) in the subgroup of SMEs than in the group of LEs (cp. Table 9). It should be noted that these rates of implementation of measures are rather high, because the companies participated in the LEEN, which support the implementation of EEMs.

\section{Discussion}

Our analyses aimed at gaining deeper insights into the relations between companies' characteristics and barriers resp. implemented measures in order to draw conclusions for a better tailoring of measures to specific companies.

To tailor instruments well to groups of companies, they should be related to relevant companies' characteristics. Trianni and Cagno (2012) highlight that characteristics additional to companies' size (e.g., experience and sector) should be taken into account when considering energy efficiency barriers and options. Furthermore, SMEs cannot be regarded as a homogenous group. Our results support these findings: companies' size turns out to be an important factor, but concerning barriers and the implementation of EEMs, several other factors turn out to be influential as well-even within the groups of SMEs and LEs. Our investigations consider companies' size and energy consumption resp. energy intensity as well as other attributes that influence implementations of EEMs like autonomy of enterprise, relatedness to customer, how EEM decisions are made and energy intensity of processes. Finding those characteristics linked to barriers or successful implementation of 
EEMs allows recommendations or customizing instruments for target groups.

Within our analyses, the barriers assessed as highest concerned the availability of time and money which somehow reflects the minor priority for energy efficiency compared to core business issues. This confirms the findings of comparable studies in the literature, e.g., Fleiter et al. (2012), where high investment costs, other priorities and unprofitable measures were found to be the most important barriers in SMEs or Thollander et al. (2007), who investigated less energy-intensive SMEs in the Swedish manufacturing sector and concluded lack of time and the low priority of energy efficiency to be the main barriers. Trianni and Cagno (2012) found lack of time and access to capital as strong barriers, especially in smaller companies. Anderson and Newell (2004) found that too high initial expenditures were the most frequently mentioned barrier, followed by a lack of staff for implementation and limited cash flow preventing implementation. They also point out institutional and bureaucratic barriers, which are hard to ascertain, because the given reasons are rather vague. A large share of companies (about 85\%; Schröter et al. 2009) base decisions on short payback rates and therefore often reject profitable measures that would have been adopted if the internal rate of return had been taken as the decision criterion (Jochem et al. 2010). This fits the findings by Cagno et al. (2015), stating that long-time strategies are a driver in implementing EEMs. Trianni and Cagno (2012) state lack of capital and insufficient information as the highest ranked barriers, matching the results of another study (Cagno et al. 2017), highlighting the importance of information and economic drivers, which show the need of support from external stakeholders and the need to understand the influencing mechanisms of specific drivers and barriers (cp. Trianni et al. 2017).

The companies we based our analyses on belong to the manufacturing sector and have in common that they were prepared to make decisions on EEMs, i.e., they were informed about their opportunities and received suggestions of suitable measures. We focused on crosscutting technologies which apply to many sectors; however, our results should be verified for different sectors than the ones of our sample. Our data is limited to companies from the manufacturing sector that participated voluntarily in the LEEN. Therefore, we can assume that our results cannot be generalized to other sectors and are likely to be biased in their level of conducted measures by the self-selection of (perhaps especially ambitious and interested) participants. Barriers due to information deficits were ranked low, but should not be underestimated - in our case, information was delivered within the project in which our sample participated.

To refine those analyses in order to describe target groups, the single subsectors should be considered as a describing variable to allow tailoring EEMs also to sectors. We did not add this kind of company characteristics, but created sector clusters, because our subsample sizes were too small for statistical relevance (mostly $<5$ companies/subsector). Especially for the definite comparisons of conducted EEMs between target groups, analyses regarding subsectors might give deeper insights. A mere differentiation between SMEs and LEs might be too vague; generally, we expect differences between the distribution of subsectors between SMEs and LEs that need to be taken into account when tailoring policy instruments to target groups. Future extension of policy instruments like the LEEN will provide larger data sets, which can be exploited to gain more insight at sector level.

Comparing findings for different industrial sectors faces the problem that studies differ by sector, technologies, time or considered barriers - as well as methodology. Additional insights could be gained from conducting analyses with a sample of sufficient size (e.g., future extension of LEEN, BMWi 2014, 2016; Dena 2015), containing subgroups with appropriate sizes for subsectors. Ideally, the sample should be representational as we observed data differences in the structure of our subgroups of SMEs that might influence the statistics.

\section{Conclusions and recommendations}

Regarding the most prevalent barriers for the implementation of EEMs, financial barriers are rated to be the highest. But, our analysis also indicates that a more detailed look needs to be taken to understand the reasons. Financial barriers can be caused by, e.g., lack of capital, bureaucratic issues, no autonomy in decisionmaking about expenditures or other priorities. High scores in this barrier are often influenced by the criteria of decision-making, e.g., if they are based simply on the amount of invested money and neglect profitability, or if the assessment of profitability is made with the unsuited risk indicator of payback periods. Our analyses revealed 
that this influence is especially high in SMEs. It can be assumed that all the suggested measures are not unaffordable per se, and generate very high profits after the break even. But most companies seem to be very risk averse or they are not aware that they vote against high profits when deciding on a two or 3 years payback period. Funding or other financial support can lower this threshold if decisions are based on the amount of expenditure. In these cases, financial restrictions are declared to be a barrier, but the financial policies introduced to tackle them might actually confirm this shortsighted way of thinking. It might be better for future policies to incentivize more forward-looking investment behaviour rather than funding the shortfall to measures which are not classified as profitable due to suboptimal decision criteria. This addresses the above mentioned need to understand the mechanisms and relations between drivers and barriers, as well as the importance of a common understanding of those between internal and external actors. The pro-active development of energyefficiency investment options by financial institutions can support companies' decision-making. In cases where unaffordable equipment still hinders the implementation of efficiency investments, contracting or leasing could be an alternative. Findings from the LEENs show that this risk perception can be lowered by exchanging experiences among energy managers in meetings of energy efficiency networks. Assuming their smaller financial possibilities, audits, and programs accompanying implementation like LEEN need to be less costly (cp. Mari:e networks, Foundation of Resource Efficiency and Climate Protection 2015). This indicates that informational measures should not be limited to the period before implementation, but are also required beyond the phase of identifying options. More hesitating companies possibly need more communication and the model of pioneer companies to be convinced. This should be kept in mind for the design of policies or when making efforts to upscale the effects.

Lack of time also is a highly ranked problem and might especially affect companies which do not have a person in charge of energy issues. This may also reflect the reluctance about transaction costs that can only partially be overcome by funding the investment costs, because implementation also takes time and effort to gather information, search for options and bargaining. Lowering these transaction costs would support the implementation of measures. Therefore, this might be another leverage point for policies: Promoting actors able to offer one-stop solutions including consulting, implementing know-how and the necessary

Table 8 Approaches to react on individual barriers and characteristics of companies regarding EEMs

\begin{tabular}{|c|c|c|}
\hline Problem area for EEMs & Influencing factors and indicators & Proposed approach \\
\hline $\begin{array}{l}\text { Lack of information/doubts } \\
\text { in benefits of measures }\end{array}$ & $\begin{array}{l}\text { Hesitation to invest/implement despite availability } \\
\text { of profitable measures, avoidance of changes }\end{array}$ & $\begin{array}{l}\text { Models of pioneer companies, information } \\
\text { on implementation process (beyond } \\
\text { recommendation of measures) }\end{array}$ \\
\hline $\begin{array}{l}\text { EEMs have low prioritylack of } \\
\text { time, expertise and resources }\end{array}$ & $\begin{array}{l}\text { Process of searching, getting informed and } \\
\text { implementing is too effortful, transaction costs } \\
\text { are too high, people in charge are overstrained }\end{array}$ & $\begin{array}{l}\text { Offer one-stop-solutions for companies to } \\
\text { outsource the process }\end{array}$ \\
\hline $\begin{array}{l}\text { Profitable measures neglected } \\
\text { due to financial issues }\end{array}$ & $\begin{array}{l}\text { Inappropriate payback periods are applied, } \\
\text { non-financial benefits are put into the rear, } \\
\text { decisions about expenses cannot be made } \\
\text { autonomous, no possibilities for financing }\end{array}$ & $\begin{array}{l}\text { Reasons should be differentiated. Depending } \\
\text { on them: } \\
\text { Incentivize consideration of longer payback } \\
\text { periods, demonstrate multiple benefits, } \\
\text { implement low-level-measures which can } \\
\text { be decided within the company, provide } \\
\text { funds or loans. }\end{array}$ \\
\hline $\begin{array}{l}\text { Heterogeneity between companies } \\
\text { within one sector, no general } \\
\text { recommendations can be given }\end{array}$ & $\begin{array}{l}\text { More influencing factors on implementation } \\
\text { of measures than sector or companies' size }\end{array}$ & $\begin{array}{l}\text { Promote individual audit; esp. for SMEs: } \\
\text { develop self-assessment tool for } \\
\text { recommendations on measures fitting to } \\
\text { company-type }\end{array}$ \\
\hline Motivational barriers & $\begin{array}{l}\text { Predominantly in LEs implementation is stated } \\
\text { difficult despite availability of profitable } \\
\text { measures }\end{array}$ & $\begin{array}{l}\text { Measures should directly affect as few } \\
\text { employees as possible, shift of decision } \\
\text { criteria from financial aspects to effort, } \\
\text { support implementation process }\end{array}$ \\
\hline
\end{tabular}


contacts to providers. Organizational efforts were found to be a motivational barrier especially for large enterprises. The second highest ranking was for difficulties in technical/structural circumstances (Table 3). This cannot be linked to specific company characteristics, so we assume that all types of companies could benefit from offers identifying the best EE options and implement them without the work effort of the company's own employees, i.e., some kind of outsourcing of the energy efficiency issue, especially given that energy is usually more of a necessity and not a company's main priority.

There are companies' characteristics that are related to specific barriers and the kind of implemented EEMs. Regarding barriers, especially the ways of decision-making and company size play a role. A differentiation between SMEs and LEs does make sense, but companies need to be considered in more dimensions than just size. The group of SMEs is more heterogeneous than LEs and are not "like LEs, just smaller". Regarding EEMs, a self-assessment tool for companies based on those attributes could constitute a compromise between finding much individual information on each company before acting and too general instruments. An example where knowledge about energy efficiency financerelated business opportunities is provided, is the Derisking Energy Efficiency Platform (DEEP). It was developed by the Energy Efficiency Financial Institutions Group (EEFIG 2017) and the data from the LEEN are also part of it.

Larger enterprises usually implement more EEMs (due to bigger budgets, a dedicated energy manager, larger scaled technologies to implement measures on or a higher awareness of their profitable measures). Some recommendations can be made regarding specific measures related to companies' characteristics and barriers, based on the higher probability of implementation in specific groups of companies. For example, ventilation and air-conditioning measures might be more appropriate for larger companies, even if energy intensity is low. The utilization of waste heat or (provided that they are indicated) measures on the building envelope also seem applicable to companies with lower energy intensities. Measures concerning motors and pumps can apparently be conducted with lower organizational effort. Measures on the production of heat and distribution of heat, cooling, and compressed air are more often implemented by LEs, but fall under the group of generally favoured measures for SMEs as well, together with measures on lighting, motors, and pumps.

Table 8 delivers some approaches beyond the typical regulative, informative and economic measures and indicates how to challenge problem areas in implementation.

Tailoring measures means reacting to individual barriers and characteristics that influence decisions and opportunities. This paper shows that size is not the only criterion to differentiate enterprises regarding EEMs and that barriers cannot be generalised to sectors. Barriers often occur on multiple levels and for more than one reason. These specific reasons need to be considered to ward off those barriers. In order to give tailored recommendations for appropriate measures without conducting individual audits, they need to be refined regarding company characteristics - besides size and sector e.g. level of experience, decision making, organisational circumstances, motivational issues and energy intensity.

Acknowledgements We thank the Federal Ministry for the Environment, Nature Conservation, Buildings and Nuclear Safety for the support of the underlying project and the many energy managers of the more than 300 companies for answering a number of questionnaires during the last 5 years. I especially want to thank Eberhard Jochem and Ursula Mielicke for their effort in the networks and also for the valuable discussions and the expertise they shared with me.

\section{Compliance with ethical standards}

Conflict of interest The authors declare that they have no conflict of interest.

Open Access This article is distributed under the terms of the Creative Commons Attribution 4.0 International License (http:// creativecommons.org/licenses/by/4.0/), which permits unrestricted use, distribution, and reproduction in any medium, provided you give appropriate credit to the original author(s) and the source, provide a link to the Creative Commons license, and indicate if changes were made.

\section{References}

Anderson, S., \& Newell, R. G. (2004). Information programs for technology adoption: the case of energy-efficiency audits. Resource and Energy Economics, 26(1), 27-50. https://doi. org/10.1016/j.reseneeco.2003.07.001.

Arens, M., \& Worrell, E. (2014). Diffusion of energy efficient technologies in the German steel industry and their impact on 
energy consumption. Energy, 73, 968-977. https://doi. org/10.1016/j.energy.2014.06.112.

Blok, K. (2004). Improving energy efficiency by five percent and more per year? Journal of Industrial Ecology, 8(4), 87-99. https://doi.org/10.1162/1088198043630478.

BMWi (2016). Energy Efficiency Networks Initiative. 500 energyefficiency networks to be established up to 2020. http://www. bmwi.de/EN/Topics/Energy/Energy-Efficiency/energyefficiency-networks-initiative.html retrieved 19.04.2016.

BMWi (Bundesministerium für Wirtschaft und Energie) (2014). National Action Plan on Energy Efficiency (NAPE): Making more out of energy. Berlin, December 2014. http://www. bmwi.de/BMWi/Redaktion/PDF/M-O/nape-national-actionplan-on-energy-efficiency,property=pdf,bereich=bmwi2012 ,sprache $=$ de, $r w b=$ true.pdf retrieved 21.04.16.

Cagno, E., Trianni, A., Spallina, G., et al. (2017). Drivers for energy efficiency and their effect on barriers: empirical evidence from Italian manufacturing enterprises. Energy Efficiency, 10(4), 855-869. https://doi.org/10.1007/s12053016-9488-x.

Cagno, E., Trianni, A., Abeelen, C., Worrell, E., \& Miggiano, F. (2015). Barriers and drivers for energy efficiency: different perspectives from an exploratory study in the Netherlands. Energy Conversion and Management, 102(2015), 26-38. https://doi.org/10.1016/j.enconman.2015.04.018.

Cagno, E., \& Trianni, A. (2014). Evaluating the barriers to specific industrial EEMs: an exploratory study in small and mediumsized enterprises. Journal of Cleaner Production, 82, 70-93. https://doi.org/10.1016/j.jclepro.2014.06.057.

Cagno, E., Worrell, E., Trianni, A., \& Pugliese, G. (2013). A novel approach for barriers to industrial energy efficiency. Renewable and Sustainable Energy Reviews, 19, 290-308. https://doi.org/10.1016/j.rser.2012.11.007.

Cooremans, C. (2013). Investment in energy efficiency by largescale consumers: an innovative audit programme. Eceee summer study 2013 conference proceedings.

DeCanio, S. J., \& Watkins, W. E. (1998). Investment in energy efficiency: do the characteristics of firms matter? The Review of Economics and Statistics, 80(1), 95-107. https://doi. org/10.1162/003465398557366.

Dena (german energy agency) (2015). dena manages office of Energy Efficiency Networks Campaign. 500 enterprise networks planned by $2020 \mathrm{http} / / \mathrm{www}$.dena.de/en/pressreleases/pressemitteilungen/dena-manages-office-of-energyefficiency-networks-campaign.html retrieved 21.04.16.

Di Nucci, M. (2012). Evaluierung des nationalen Teils der Klimaschutzinitiative des Bundesministeriums für Umwelt, Naturschutz und Reaktorsicherheit. Anhang A-13 zum Endbericht. Einzelprojektevaluierung Lernende Energieeffizienz- und Klimaschutz-Netzwerke: 30 Pilot$\mathrm{Netzwerke} \mathrm{und} \mathrm{Entwicklung} \mathrm{von}$ Investitionsberechnungshilfen. NKI-Evaluierung. BMUB.

Ecofys, Fraunhofer ISI (2010). Energy Savings 2020. How to triple the impact of energy saving policies in Europe, final report. On behalf of the European Climate Foundation \& Regulatory Assistance Project. http://roadmap2050. eu/contributing_studies.

EEFIG (Energy Efficiency Financial Institutions Group) (2017). De-risking Energy Efficiency Platform (DEEP). http://deep. eefig.eu/ retrieved 08.02.2017.
Eichhammer, W. (2013). Analysis of a European reference target system for 2030. Report by Fraunhofer ISI for the Coalition for Energy Savings. Karlsruhe. http://energycoalition. eu/sites/default/files/Fraunhofer\%20ISI ReferenceTargetSystemReport.pdf retrieved 12.04.16.

Energy Efficiency Financial Institutions Group EEFIG (2015). Energy Efficiency - the first fuel for the EU Economy. How to drive new finance for energy efficiency investments. Final report covering Buildings, Industry and SMEs. F e bruary 2015 . https:// e c.e uropa. eu/energy/sites/ener/files/documents/Final\%20Report\%20 EEFIG\%20v\%209.1\%2024022015\%20clean\%20 FINAL\%20sent.pdf retrieved 12.04.16.

European Commission (EC) (2003): Commission recommendation of 6 May 2003 concerning the definition of micro, small and medium-sized enterprises (notified under document number C(2003) 1422). http://eur-lex.europa. eu/LexUriServ/LexUriServ.do?uri=OJ:L:2003:124:0036 :0041:en:PDF. retrieved: 19.04.2016.

European Commission (EC) (2012): Directive 2012/27/EU of the European Parliament and of the Council of 25 October 2012 on energy efficiency, amending Directives 2009/125/EC and 2010/30/EU and repealing directives 2004/8/EC and 2006/32/EC (Official Journal of the European Union L315/ 1 from 11 November 2012). http://eur-lex.europa.eu/legalcontent/EN/TXT/PDF/?uri=CELEX:32012L0027 retrieved 21.04.16.

Fleiter, T. (2013). Der deutsche Policy-Mix zur Steigerung der Energieeffizienz in Unternehmen- eine modellbasierte ex-ante Untersuchung. 8. Internationale Energiewirtschaftstagung an der TU Wien (IEWT 2013).

Fleiter, T., Schleich, J., \& Ravivanpoong, P. (2012). Adoption of energy-efficiency measures in SMEs-An empirical analysis based on energy audit data from Germany. Energy Policy, 51(2012), 863-875.

Florax, R. J., De Groot, H. L., \& Mulder, P. (2011). Improving energy efficiency through technology: trends, investment behaviour and policy design. Cheltenham: Northampton, Edward Elgar Publishing.

Foundation of Resource Efficiency and Climate Protection (2015). Together reducing energy cost (in German). http://www. marie.streks.org/willkommen.html retrieved: 28.03.17.

Frahm, B.-J., Gruber, E., Mai, M., Roser, A., Fleiter, T., \& Schlomann, B. (2010). Evaluation des Förderprogramms "Energieeffizienzberatung" als eine Komponente des Sonderfonds' Energieeffizienz, in kleinen und mittleren Unternehmen (KMU). Karlsruhe: IREES/Fraunhofer ISI 2010.

Fraunhofer ISI, Vienna, T. U., \& PwC (2014). Study evaluating the current energy efficiency policy framework in the EU and providing orientation on policy options for realising the costeffective energy-efficiency/saving potential until 2020 and beyond. Report on behalf of DG ENER. Vienna: Karlsruhe.

Granade, H.C., Creyts, J., Derkach, A., Farese, P., Nyquist, S., Ostrowski, K. (2009). Unlocking energy efficiency in the U.S. economy. McKinsey\&Company.

Gruber, E., \& Brand, M. (1991). Promoting energy conservation in small and medium-sized companies. Energy Policy, 19(3), 279-287. https://doi.org/10.1016/0301-4215(91)90152-E.

Harris, J., Anderson, J., \& Shafron, W. (2000). Investment in energy efficiency: a survey of Australian firms. Energy 
Policy, 28(12), 867-876. https://doi.org/10.1016/S03014215(00)00075-6.

Howell, D. (2012). Statistical methods for psychology. Cengage Learning.

IEA (International Energy Agency). (2012). World energy outlook 2012. Paris: OECD/IEA http://www.iea.org/.

IEA (International Energy Agency). (2015). Accelerating energy efficiency in small and medium-sized enterprises. Powering SMEs to catalyse economic growth. Paris: IEA (International Energy Agency).

Jaffe, A. B., \& Stavins, R. N. (1994). The energy-efficiency gapwhat does it mean? Energy Policy, 22(10), 804-810. https://doi.org/10.1016/0301-4215(94)90138-4.

Jochem, E., Gruber, E., et al. (2006). Modellvorhaben Energieeffizienz-Initiative Region Hohenlohe zur Reduzierung der CO2-Emissionen. Schlussbericht für das Ministerium für Umwelt und Verkehr Baden-Württemberg.

Jochem, E., \& Gruber, E. (2007). Local learning networks on energy efficiency in industry - Successful initiative in Germany. Applied Energy, 84(2007), 806-816. https://doi. org/10.1016/j.apenergy.2007.01.011.

Jochem, E., Mai, M., \& Ott, V. (2010). Energieeffizienznetzwerke - beschleunigte Emissionsminderungen in der mittelständischen Wirtschaft. Zeitschrift für Energiewirtschaft, 34, 21-28. https://doi.org/10.1007 /s12398-010-0002-4.

Kaiser, H. F., \& Rice, J. (1974). Little jiffy, mark IV. Educational and psychological measurement, 34, 11-117.

Lapillonne, B., Schlomann, B., Pollier, K., Reuter, M., Tariq, S., Wohlfarth, K. (2015). Energy efficiency trends and policies in industry. An analysis based on the ODYSSEE and MURE databases. September 2015. http://www.odyssee-mure. eu/publications/br/ retrieved 12.04.16.

Leinweber, F. (2014). Clustering of energy efficiency measures from the monitoring phase of the project " 30 pilotNetzwerke". Bachelor thesis, Karlsruhe Institute of Technology, unpublished.

Price, L., Lu, H. (2011). Industrial energy auditing and assessments: a survey of programs around the world: ECEEE summer study 2011, June 6-11, Presquíle de Giens.

Ringel, M., Schlomann, B., Krail, M., Rohde, C. (2016). Towards a green economy in Germany? The role of energy efficiency policies. Applied energy 2016 (available online).

Rogge, K. S., \& Reichardt, K. (2013) Towards a more comprehensive policy mix conceptualization for environmental technological change: A literature synthesis, Working Paper Sustainability and Innovation, No. S3/2013.

Rohde, C., Köwener, D., Mielicke, U., Nabitz, L. (2015). Learning energy efficiency networks - evidence based experiences from Germany. ACEEE Summer Study 2015.

Schröter, M., Weißfloch, U., \& Buschak, D. (2009). Energieeffizienz, in der Produktion - Wunsch oder Wirklichkeit? Energieeinsparpotentiale und Verbreitungsgrad energieeffizienter Techniken. Fraunhofer ISI, Karlsruhe: Modernisierung der Produktion.
Sorrell, S., Mallett, A., \& Nye, S. (2011). Barriers to industrial energy efficiency: a literature review. Working Paper 10/ 2011. Development Policy, Statistics and Research Branch. Vienna: United Nations Industrial Development Organization. http://sro.sussex.ac.uk/53957/1/WP102011_ Barriers_to_Industrial_Energy_Efficiency_-_A_Literature Review.pdf. Accessed $23 \mathrm{Feb} 2018$.

Statistisches Bundesamt (2013). Statistik zum Anteil kleiner und mittlerer Unternehmen: https://www.destatis. de/DE/ZahlenFakten/GesamtwirtschaftUmwelt/ UnternehmenHandwerk/KleineMittlereUnternehmen Mittelstand/Tabellen/Insgesamt.htm1; jsessionid= EA509337513F4CCD1F0224CB79A00C26.cae2 and https://www.destatis.de/DE/ZahlenFakten/ GesamtwirtschaftUmwelt/UnternehmenHandwerk/ KleineMittlereUnternehmenMittelstand/Tabellen/ VerarbeitendesGewerbe.html, retrieved 12.04.16.

Stern, P. C. (1992). What psychology knows about energy conservation. American Psychologist, 47(10), 1224-1232. https://doi.org/10.1037/0003-066X.47.10.1224.

Stern, P.C., Aronson, E. (1984). Eds. Energy use: the human dimension, W.H freeman, 0716716216 , New York.

Thollander, P., Danestig, M., \& Rohdin, P. (2007). Energy policies for increased industrial energy efficiency: evaluation of a local energy programme for manufacturing SMEs. Energy Policy, 35(11), 5774-5783. https://doi.org/10.1016/j. enpol.2007.06.013.

Thollander, P., Cornelis, E., Kimura, O., Morales, I., Jiménez, R. Z., Backlund, S., Karlsson, M., Söndertröm, M. (2014). The design and structure of effective energy end-use policies and programs towards industrial SMEs. ECEEE 2014 proceedings.

Trianni, A., \& Cagno, E. (2012). Dealing with barriers to energy efficiency and SMEs: some empirical evidences. Energy, 37(1), 494-504. https://doi.org/10.1016/j. energy.2011.11.005.

Trianni, A., Cogno, E., \& Farné, S. (2016). Barriers, drivers and decision-making process for industrial energy efficiency: a broad study among manufacturing small and medium-sized enterprises. Applied Energy, 162, 1537-1551. https://doi. org/10.1016/j.apenergy.2015.02.078.

Trianni, A., Cagno, E., Marchesani, F., \& Spallina, S. (2017). Classification of drivers for industrial energy efficiency and their effect on the barriers affecting the investment decisionmaking process. Energy Efficiency, 10(1), 199-215. https://doi.org/10.1007/s12053-016-9455-6.

Wohlfarth, K., Eichhammer, W., Schlomann, B., Mielicke, U. (2016). Learning networks as an enabler for informed decisions to target energy-efficiency potentials in companies Journal of Cleaner Production (in press).

Worrell, E., Bernstein, L., Roy, J., Price, L., \& Harnisch, J. (2009). Industrial energy efficiency and climate change mitigation. Energy Efficiency, 2(2), 109-123. https://doi.org/10.1007 /s12053-008-9032-8. 